\section{LETTER TO THE EDITOR \\ Professionalism and the police}

Sir, I read with interest the $B D J$ In Practice article $^{1}$ discussing how to manage contact with the police and the ramifications for Dental registrants if subject to criminal proceedings. Much of the content was most reassuring and the tips if stopped and searched helpful, in the unlikely event of such an occurrence. However, a number of points raised I found less reassuring:

$\rightarrow$ 'The police do not always keep their 'promise' when offering cautions'

$\rightarrow$ 'The officer may be offering a caution to extract a confession from you'

$\rightarrow$ 'Following the steps above encourages the police to behave properly'

$\rightarrow$ 'Do not be manipulated by officers'.

Much as GDC registrants have clear standards to comply with, ${ }^{2}$ so do the police. ${ }^{3}$ It is reassuring that reflective practice so important to members of the dental team appears equally as important to the police. Great emphasis is placed on transparency, openness and effective complaints handling.

Perhaps the two professional bodies have more in common than we might first think on initial inspection!

\section{E. McColl, Plymouth}

References

1. Lakhani T. How to respond if you are stopped by a police officer. BDJ In Pract 2021; 34: 27-28.

2. General Dental Council. Standards for the Dental Team. Available online at: www.gdc uk.org (Accessed February 2021).

3. Home Office. Home Office Guidance. Conduct, Efficiency and Effectiveness: Statutory. Guidance on Professional Standards, Performance and Integrity in Policing Available online at: https://assets.publishing. service.gov.uk/government/uploads/system/ uploads/attachment_data/file/863820/ Home_Office_Statutory_Guidance_0502.pdf (Accessed February 2021).

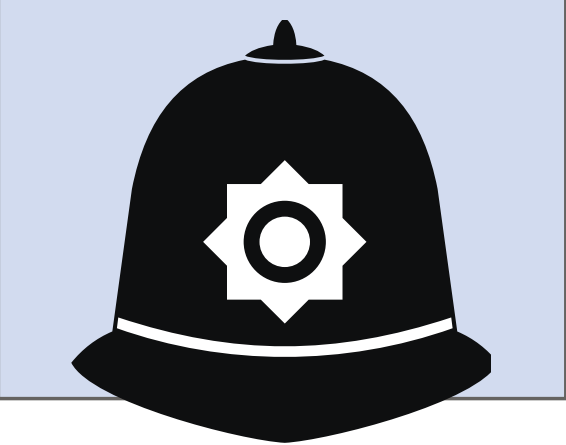

\title{
Uber ruling - what will it mean?
}

Many dentists (both principals and associates) will be aware that there was a Supreme Court judgement that ruled Uber drivers must be treated as workers rather than self-employed.

The five key facts in the Uber judgement were:

1. Remuneration was controlled by Uber including the amount paid to drivers and whether to refund passengers.

2. Drivers have no ability to negotiate the terms they contract with Uber on or the terms on which they transport passengers.

3. Once the driver is logged into the Uber App, they have limited power over their operations, placing them in a position of subordination. For example, the driver is not informed of the intended destination before accepting the fare and Uber can $\log$ the driver out if their acceptances or cancellations are unsatisfactory.

4. Uber exercise significant control over the service provided to passengers as the cars are vetted, the software is integral, Uber control the information provided to drivers, and drivers are monitored.

5. The relationship between the driver and the passenger is restricted to a minimum, preventing the driver from establishing a relationship which benefits their 'business' as a driver, which is specifically prohibited by Uber in any event.

This has meant that the political hot potato of whether associates should be self-employed or not has again risen its head. From a tax perspective, this has been covered in previous NASDAL releases and the position is still very clear - HMRC guidance contained in 'Employment Status Manual ESM4030 Particular occupations: dentists' states:

'It should be noted that there are standard forms of agreement for 'associate' dentists which have been approved by the British Dental Association (BDA) and the Dental Practitioners Association (DPA)(sic). These agreements relate to dentists practicing as associates in premises run by another dentist.

Where these agreements are used and the terms are followed, the income of the associate dentist is assessable under trading income rules and not as employment income. In these circumstances the dentist is liable for Class 2/4 NICs and not Class 1 NICs.
The NHS General Dental Services Contract, which came into force from 1 April 2006, provides for less fluctuation in associate dentist's income. However, providing the associate dentist continues to be responsible for paying their share of laboratory fees etc. for work relating to their patients and other terms of the standard agreement are followed, the above guidance will still apply.'

Some have expressed concern that these potential employment rights could have an effect on the vicarious liability of the associate as well as worker benefits. If principals became liable for maternity leave and holidays, this could drive associate pay down and employment might actually be a more attractive option for all moving forward. However, one of the key factors in the judgement is that the Uber drivers could not substitute or send a locum in to do their work. They had to perform it personally. This is not always the case for dentists. They usually have the right to substitute in their contract and this is why it is key that contracts are abided by and not changed without expert advice.

Alan Suggett, specialist dental accountant and partner in UNW LLP said: 'What is perhaps less clear now is that arguably an associate could be considered self-employed by HMRC and yet be a 'worker' from an employment law perspective. Perhaps where the associates are different to most Uber drivers is that they want to be self-employed.'

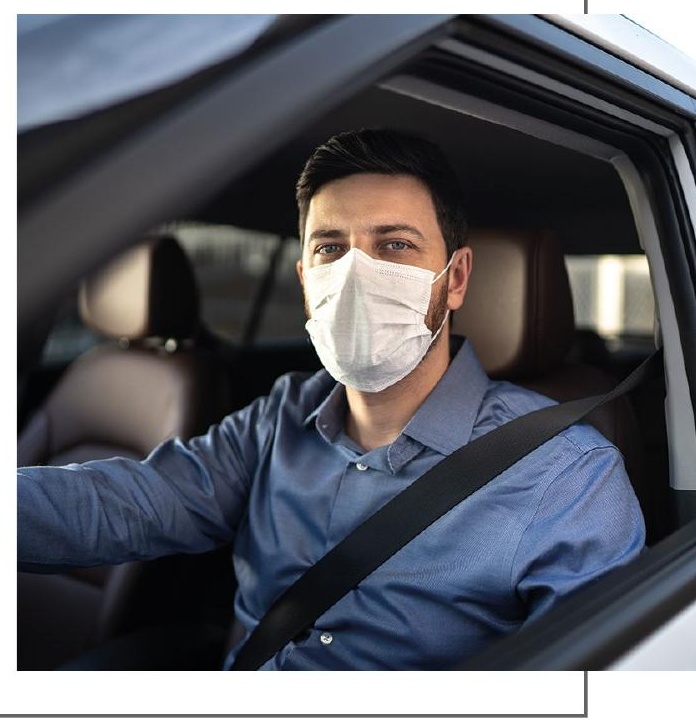

